\title{
Micropulse laser trabeculoplasty as an adjuvant treatment for uncontrolled open angle glaucoma
}

\author{
Diego Valera Cornejo ${ }^{1}$, Waldo Loayza Gamboa ${ }^{1,2}$, Julio Herrera Quiroz c ${ }^{2}$, Rosa Alvarado Villacorta ${ }^{1}$, Luis Córdova Crisanto ${ }^{1}$, Vanessa \\ Valderrama Albino ${ }^{1,2}$ and Nahuel Pantoja Dávalos ${ }^{2}$ \\ ${ }^{1}$ Vista Medical Eye Center, Perú \\ ${ }^{2}$ National Institute of Ophthalmology of Peru, Peru
}

\begin{abstract}
Background: We describe the pressure lowering effect of micropulse laser trabeculoplasty (MLT) in patients with medically uncontrolled open angle glaucoma $(\mathrm{OAG})$.

Materials and methods: We retrospective reviewed 30 eyes with Open angle Glaucoma (OAG) at the Vista Clinic in Lima, Peru. A single session of MLT treatment was delivered using a $532 \mathrm{~nm}$ Frequency doubled Nd. YAG laser to $360^{\circ}$ of the trabecular meshwork with a power of $1000 \mathrm{~mW}, 25 \%$ of duty cycle, and $300 \mathrm{~ms}$. of exposure. The intraocular pressure (IOP) was measured at baseline and at 1 day, 1 week, 3, 6 months post-treatment and were followed up for one last control.

Results: The mean baseline IOP was $15.6 \mathrm{mmHg}$ and in the last control was $12.8 \mathrm{mmHg}$, mean follow up time of 19 months (+/- $10 \mathrm{SD})$. The mean reduction of IOP in the first day was $1.6 \mathrm{mmHg}( \pm 2.6 \mathrm{SD})$ and $1.2 \mathrm{mmHg}( \pm 3.3 \mathrm{SD})$ in the last follow up. The mean percentage of IOP reduction was $17.9 \%$ and 7 eyes $(40 \%)$ had IOP reduction greater than $20 \%$. No statistical difference in relation to demographics characteristics of the patients. The greatest reduction was achieved in the first day with a median of 2.00 (P 0.001). A tendency to achieve higher reduction of IOP in patients with higher baseline IOP was found, but was not statistical significant. No change in the number of medication used and no adverse reactions occurred.
\end{abstract}

Conclusion: MLT was safe and can be effective in reducing IOP in medically uncontrolled OAG.

\section{Introduction}

Glaucoma is the second leading cause of blindness worldwide and the leading cause of irreversible blindness, accounting for $8 \%$ of all blindness, affecting an estimated 3.12 million blind people in the world [1]. The World Heatlh Organization (WHO) estimated that $12.3 \%$ of blindness was cause by glaucoma in 2002 [2]. There will be 79.6 million with glaucoma by 2020 , and of these, $74 \%$ will have Open angle glaucoma (OAG). Women will comprise 55\% of OAG, 70\% of angle closure glaucoma (ACG), and 59\% of all glaucoma in 2010. Asians will represent $47 \%$ of those with glaucoma and $87 \%$ of those with ACG. Bilateral blindness will be present to 5.9 and 5.3 million people in 2020 , respectively [3]. The prevalence of OAG in hispanic subjects was $1.97 \%$ (CI 95\%), increasing from $0.50 \%$ at the age of $41-49$ years to $12.63 \%$ at the age of 80 years [4]. In Peru the prevalence was 2\% (CI 95\%) [5].

The main aim of the treatment is to lower the intra ocular pressure (IOP) in order to stop the retinal nerve fiber layer damage and visual field loss. Topical antiglaucoma medications are used before surgery since this last one is related to some complications, despite his efficiency to lower the IOP. The use of laser in the trabeculum was initially described by Wise and Witter in 1979 with the Argon Laser trabeculoplasty (ALT) [6], and then in 1995 Latina and Park begin to use the Selective Laser trabeculoplasty (SLT) $[7,8]$, since then, they become widely use for the treatment of OAG, and demonstrated to have similar efficacy to lower the IOP in comparison to topical medications avoiding their side effects [9]. Other several studies demonstrated the same efficacy between these two procedures, however SLT has the advantage that it does not leave a noticeable scar on the trabeculum and is repeatable [10-16].
More recently, micropulse laser trabeculoplasty (MLT) has been introduced, and its effects were compared with ALT [17], despite the few data reported, it showed promising results [18-20]. This technology use a dutycycle algorithm that delivers subthreshold treatment to ocular tissues without scar formation, making it safe to apply the laser even directly over the fovea and its widely use for the treatment of several maculopathies [21-23] .It minimizes time in which laser induced heat can spread to adjacent tissues resulting in absence of collateral damage with an induced biological response to the trabecular meshwork that decrease the IOP [24-27] and like SLT it doesn't damage the trabeculum but its efficiency it's still on debate.

We report on the pressure lowering effect of MLT in patients with medically uncontrolled open angle glaucoma of Peruvian eyes in Lima, Peru.

\section{Material and methods}

\section{Study design}

This was a retrospective chart review of patients treated with MLT between the years 2014 and 2016. The study was carried out at the

Correspondence to: Diego Alejandro Valera Cornejo, Cayetano Heredia National University, Attending Ophthalmologist of the Vista Eye Medical Center Lima - Perú, Jirón Caracas 2410 Jesús María Lima Perú, Tel: 51 (01) 6413217, 51 1 987017264; E-mail: diegoavalera@gmail.com

Key words: open angle glaucoma, trabeculoplasty, diode laser, micropulse, subthreshold

Received: November 20, 2017; Accepted: December 19, 2017; Published: December 23, 2017 
Vista Medical Eye Center, Lima, Peru. The study complied with the Declaration of Helsinki. The ethics committee of San Marcos University approved the study, and written informed consent was obtained from the patients before the procedure.

\section{Eligibility and exclusion criteria}

The objectives were to review the efficacy and safety of MLT in Peruvian adults with medically uncontrolled OAG (including pseudoexfoliation and pigmentary glaucoma) that was defined as a persistently high IOP or progression of visual field/retinal nerve fiber layer loss even with the application of one or a combination of two, three or four topical medications and/or with oral hypotensive medical treatment. We also set out to analyze the effect of various criteria such, age, sex, baseline IOP and previous surgery on the outcome.

The inclusion criteria included those with more than 40 years of age with POAG with uncontrolled medical therapy and with at least $50 \%$ gonioscopically open angles. Exclusion criteria included failure to obtain consent, patients with poor access to the angle on gonioscopy, patient who received prior laser trabeculoplasty, concomitant infection or inflammation, and infirmity sufficient to prevent adequate application of the laser.

\section{Subjects, follow up and measure outcome}

The procedure was explained to the patients, and the consent was obtained in writing. Patients were evaluated at 1 day, 1 week, 1 month, 3 months, 6 months, and one last follow up. At each visit, anterior segment examination, best corrected visual acuity and IOP measurements were performed. The IOP was measured by the Goldmann applanation tonometry (AT900, Haag-Streit, Köniz, Switzerland). The definition of MLT success on the other hand is defined as an IOP reduction of $>20 \%$ after MLT.

\section{Laser technique}

We did MLT with the frecuency doubled Nd. YAG laser (Supra 532 Laser System; Quantel Medical, Clermont-Ferrand, France). The micropulse laser settings, were as follows: $300 \mu \mathrm{m}$ spot size diameter, $1000 \mathrm{~mW}$ power, and $300 \mathrm{~ms}$ duration with $15 \%$ duty cycle.

All MLT procedures were performed by a single surgeon. After a drop of topical anesthetic (Proximetacaine 0.5\%), the patient was seated at the slit lamp and a laser antireflective coated Goldmann threemirror lens (Ocular Instruments, Bellevue, WA, USA) was placed on the eye to be treated. The laser was focused on the anterior trabecular meshwork and confluent applications were administered over $360^{\circ}$. Since no visible laser induced tissue change endpoint is produced at the TM, we relied on the surgeon's judgment and skill, resulting in a variable number of confluent and even overlapping spots. The total number of laser applications delivered to each eye was recorded after each treatment. Immediately after the treatment, diclofenac $0.1 \%$ eye drops were administered and continued three times daily for five days. The patients were maintained on their pre-treatment drug regimen. Patients received a single MLT treatment and no retreatment was done.

\section{Statistics}

Central tendency and dispersion values were determined for quantitative variables, as well as absolute and relative frequencies for categorical variables. The post-treatment values were compared with the baseline values using the Wilcoxon signed-rank test with significance corresponding to a $p$-value of $<0.05$. The Spearman rank correlation coefficient was used to assess the relationship between baseline IOP and the percent reduction on the last follow up. Data were collected in a retrospective fashion from chart reviews and were analyzed using Stata $^{\circledR}$ version 14 (StataCorp. 2015, Stata Statistical Software: Release 14. College Station, Texas, US: StataCorp LP.)

\section{Results}

The baseline demographic characteristics are listed in Table 1. In all, 30 eyes were evaluated in the study. The mean age of the patients was 70 years, with a female/male ratio of 3:1. The average pretreatment cup-disc ratio was $0.85,86.7 \%$ of the patients were on medications, $26.7 \%(n=8)$ of patients has previous glaucoma surgery and $76.7 \%$ of patients were phakic. The mean follow-up period was 19 months (SD \pm 10) with a maximum follow-up of 36 months (Table 1).

An average of 120 burns was applied per session. The mean pre laser IOP was $15.6 \mathrm{mmHg}(\mathrm{SD} \pm 3.5)$ and the post-laser IOP at 1 day, 1 week, 1 month, 3 months, 6 months and in the last follow up, was $14.0,14.7,14.9,25.2,14.4$ and $12.8 \mathrm{mmHg}$ respectively (Figure 1). The average absolute reduction in IOP at the first day, 3 months, and last follow up was 1.60, 1.1 and $1.2 \mathrm{mmHg}$ respectively (Table 2). Thus, post laser immediate drop (at the first day) has a median of $2.00 \mathrm{mmHg}$ and was statistical significant (CI -3.00 - 0, P,0.0012) (Table 3). At first day, the IOP was reduced by $10.3 \%$ and in the last follow up was $17.9 \%$. Table 4 shows the distribution of the percentage of eyes with IOP reduction $>20 \%$, and $<20 \%$ through the entire follow up. $30 \%(\mathrm{~N}=9)$ of the eyes had an IOP reduction $>20 \%$ at the first day and $41 \%(n=7)$ in the last control (Figure 2). Some patients were lost in the followup. Additionally, there was a trend towards greater IOP reduction with higher base line IOP but this was not statistically significant due to the small sample and design of the study (Figure 3).

The patients were maintained on their pre-treatment drug regimen and no changes were applied in their medications. None of the patients had significant inflammatory reaction that was documented at the next follow-up. There were no pressure spikes. At the last followup no patient had peripheral anterior synechiae. Visual acuity were unchanged in all eyes. There was no statistically significant difference in IOP reduction between groups (age, cup to disc ratio, phakic state, number of medications, previous glaucoma surgery)

Table 1. Baseline demographic characteristics $(n=30)$

\begin{tabular}{|l|c|c|}
\hline Characteristics & Mean & SD \\
\hline Age (years) & 70.20 & \pm 10.5 \\
\hline Cup/Disc ratio & 0.85 & \pm 0.12 \\
\hline Follow up (months) & 19.00 & \pm 10 \\
\hline Sex & $\mathbf{n}$ & $\mathbf{\%}$ \\
\hline Female & 22 & $73.3 \%$ \\
\hline Male & 8 & $26.7 \%$ \\
\hline Previous Glaucoma surgery & & \\
\hline None & 22 & $73.3 \%$ \\
\hline Trabeculectomy & 6 & $20.0 \%$ \\
\hline Drainage device & 2 & $6.7 \%$ \\
\hline Number of glaucoma medication & 4 & $13.3 \%$ \\
\hline 0 & 8 & $26.7 \%$ \\
\hline 1 drop & 8 & $26.7 \%$ \\
\hline 2 drops & 6 & $20.0 \%$ \\
\hline 3 drops & 4 & $13.3 \%$ \\
\hline 4 drops & & $76.7 \%$ \\
\hline Lens status & 23 & $23.3 \%$ \\
\hline Phakic & 7 & \\
\hline Pseudophakic & & \\
\hline
\end{tabular}


Table 2. Mean intraocular pressure (IOP) with standard deviation and mean IOP reduction from baseline at various time points up to the last follow up

\begin{tabular}{|c|c|c|c|c|c|c|c|}
\hline & Baseline & 1 day & 1 week & 1 month & 3 months & 6 months & Last follow up \\
\hline & $\mathrm{N}=30$ & $\mathrm{~N}=30$ & $\mathrm{~N}=26$ & $\mathrm{~N}=22$ & $\mathrm{~N}=20$ & $\mathrm{~N}=20$ & $\mathrm{~N}=17$ \\
\hline Mean IOP (mm Hg) & 15.6 & 14 & 14.7 & 14.9 & 15.2 & 14.4 & 12.8 \\
\hline Standard Deviation & \pm 3.5 & \pm 3.2 & \pm 3.5 & \pm 4.9 & \pm 5.3 & \pm 3.2 & \pm 2.6 \\
\hline Min - Max & $10-25$ & $9-22$ & $10-24$ & $10-30$ & $10-30$ & $11-24$ & $08-20$ \\
\hline IQR & $(13-17)$ & $(12-16)$ & $(12-16)$ & $(12-15)$ & $(12-16)$ & $(12-16)$ & $(12-14)$ \\
\hline Mean IOP reduction \% & & $10.2 \%$ & $5.7 \%$ & $4.4 \%$ & $2.5 \%$ & $7.7 \%$ & $17.9 \%$ \\
\hline
\end{tabular}

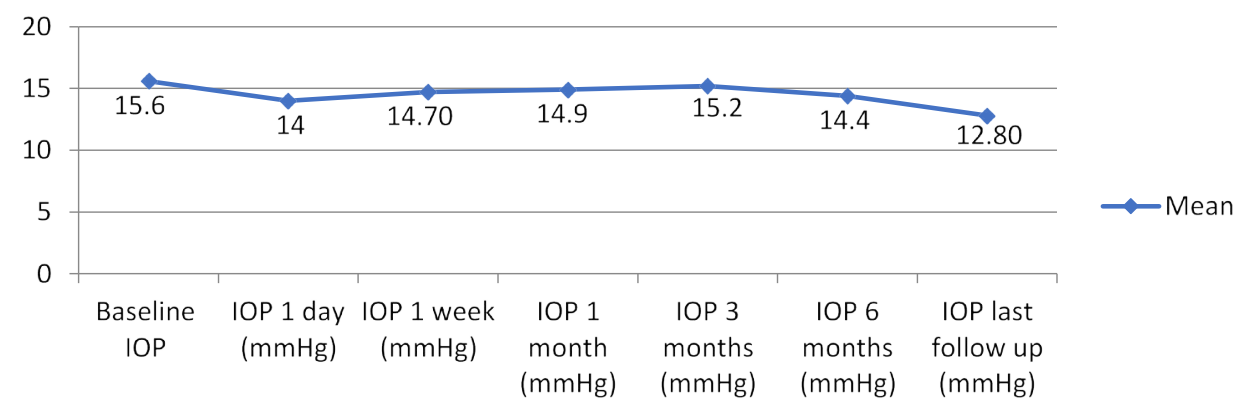

Figure 1. Mean intraocular pressure (IOP) at various time points up to the last follow up

reduction $>20 \%$ from baseline

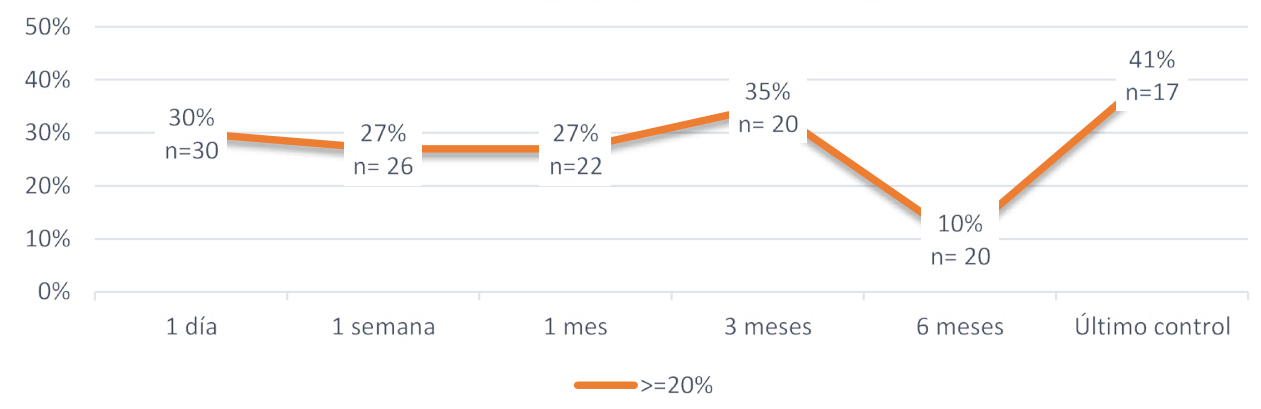

Figure 2. Percentage of eyes with intraocular pressure (IOP) reduction $>20 \%$ from baseline

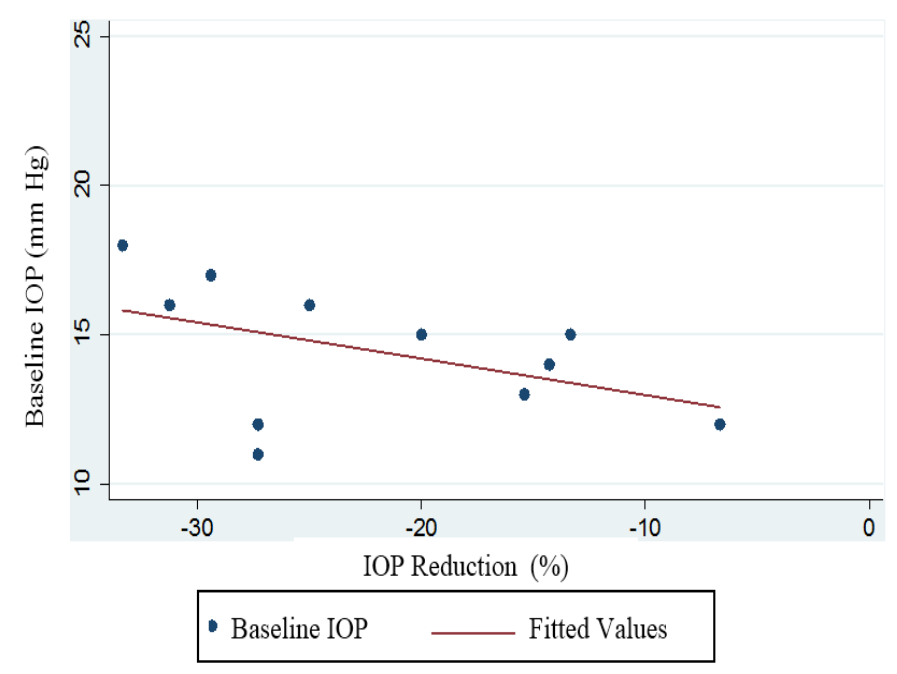

Figure 3. Baseline IOP and Percentage of reduction
Table 3. IOP reduction from baseline (median and IQR) at various time points up to the last follow up and $P$ value

\begin{tabular}{|l|c|c|c|}
\hline IOP Reduction & Median & IQR & p-Value* \\
\hline 1 day $(\mathrm{mmHg})$ & -2.00 & $(-3$ a 0$)$ & $\mathbf{0 . 0 0 1}$ \\
\hline 1 week $(\mathrm{mmHg})$ & -1 & $(-3$ a 1$)$ & 0.0997 \\
\hline 1 months $(\mathrm{mmHg})$ & -1 & $(-3$ a 0$)$ & $\mathbf{0 . 0 2 6 3}$ \\
\hline 3 months $(\mathrm{mmHg})$ & -2 & $(-3$ a 1$)$ & 0.3191 \\
\hline 6 months $(\mathrm{mmHg})$ & 0.5 & $(-1,5$ a 2$)$ & 0.986 \\
\hline Last follow up $(\mathrm{mmHg})$ & -2 & $(-3$ a 1$)$ & 0.1106 \\
\hline * Wilcoxon signed rank test, IQR: interquartile range & & \\
\hline
\end{tabular}

Table 4. Distribution of the percentage of eyes with IOP reduction $>20 \%$, and $<20 \%$ through the entire follow up

\begin{tabular}{|c|c|c|c|}
\hline & & \multicolumn{2}{|c|}{ IOP Reduction \% * } \\
\hline Follow up & $\mathbf{n}$ & $>=\mathbf{2 0} \%$ & $<\mathbf{2 0 \%}$ \\
\hline 1 day & 30 & $9(30 \%)$ & $21(70 \%)$ \\
\hline 1 week & 26 & $7(27 \%)$ & $19(73 \%)$ \\
\hline 1 month & 22 & $6(27 \%)$ & $16(73 \%)$ \\
\hline 3 months & 20 & $7(35 \%)$ & $13(65 \%)$ \\
\hline 6 months & 20 & $2(10 \%)$ & $18(90 \%)$ \\
\hline Last follow up & 17 & $7(41 \%)$ & $10(59 \%)$ \\
\hline
\end{tabular}




\section{Discussion}

MLT does not result in any cellular destruction, scarring, or collateral damage because it uses a pulsed laser treatment (15\% duty cycle) rather than a continuous laser wave (100\% duty cycle) into the trabeculum [24]. Despite the few data demonstrating the safety and potential that MLT has to decrease the IOP, its use is still debatable.

The mean drop in IOP was $17.9 \%$ in the last follow up and is lower than that obtained in previous studies, Ingvoldstad et al. [17] and Detry-Morel et al. [26], reported IOP reductions of $18.3 \%$ and $12.2 \%$ respectively with MDLT in three months. Gossage et al. [18] obtained a drop of $18 \%$ in IOP at 4 months. Fea et al. [20] carried out MDLT in a cohort of 20 patients, with a follow up time of 12 months, they achieve an IOP reduction of $21.3 \%$ and ten of the 15 eyes (66.7\%) had an IOP reduction $>20 \%$ in comparison with other studies that only $35.7 \%$ of patients achieved such a reduction [26]. Others like Lee et al. [27] had an IOP reduction of $19.5 \%$ at 6 months with an IOP reduction higher than $20 \%$ at the first month of $72.9 \%(n=35)$ of the patients. Unlike other studies, we only achieved an IOP reduction higher than $20 \%$ in $35 \%(\mathrm{n}=7)$ at three months and $41 \%(\mathrm{n}=7)$ at the last follow up. In a retrospective case series carried out by Babaloba [28] the average drop in IOP was $17.2 \%$ and was sustained trough time with a mean follow up of 5 months.

Additionally, we found a trend towards greater IOP reduction with higher base line IOP but this was not statistically significant due to the small sample and design of the study, and it is correlated with several studies that evaluates the predictive factors for success with SLT $[29,30]$. Unlike other studies, we did not observe significant inflammatory response [20,26].

There are several limitations on this study: a small number of patients, it is a retrospective review of cases, and therefore, patients were not examined at specific time intervals, there was a considerable loss of the number of patients through the follow up. $26.7 \%$ of the patients had a previous glaucoma surgery and most of the patients were on topical medical treatment, so there could be many confounding effects.

\section{Conclusion}

MLT appears to be safe and a useful adjunct to conservative treatment in order to decrease the IOP in some patients with uncontrolled OAG. It also offers more patient comfort during and after the procedure. Nevertheless, the effect may not be long lasting in all cases, and some patients will not respond to the therapy. It is, however, repeatable because damage to the trabeculum is minimal.

In our opinion subthreshold micropulse laser device can also be used for other ophthalmic applications, thus reducing the economic burden of treatment. Randomized clinical trials are needed to compare MLT with current IOP-lowering laser therapies, or antiglaucoma medications.

\section{References}

1. Pascolini D, Mariotti SP (2012) Global estimates of visual impairment: 2010. $\mathrm{Br} J$ Ophthalmol 96: 614-618. [Crossref]

2. Resnikoff S, Pascolini D, Etya'ale D, Kocur I, Pararajasegaram R, et al. (2004) Global data on visual impairment in the year 2002. Bull World Health Organ 82: 844-851. [Crossref]

3. Quigley HA, Broman AT (2006) The number of people with glaucoma worldwide in 2010 and 2020. Br J Ophthalmol 90: 262-267. [Crossref]

4. Quigley HA, West SK, Rodriguez J, Munoz B, Klein R, et al. (2001) The prevalence of glaucoma in a population-based study of Hispanic subjects: Proyecto VER. Arch Ophthalmol 119: 1819-1826. [Crossref]
5. Campos B, Cerrate A1, Montjoy E1, Dulanto Gomero V1, Gonzales C2, et al. (2014) [National survey on the prevalence and causes of blindness in Peru]. Rev Panam Salud Publica 36: 283-289. [Crossref]

6. Wise JB, Witter SL (1979) Argon laser therapy for open-angle glaucoma. A pilot study. Arch Ophthalmol 97: 319-322. [Crossref]

7. Latina MA, Park C (1995) Selective targeting of trabecular meshwork cells: in vitro studies of pulsed and CW laser interactions. Exp Eye Res 60: 359-372. [Crossref]

8. Latina MA, Sibayan SA, Shin DH, Noecker RJ, Marcellino G (1998) Q-switched 532$\mathrm{nm}$ Nd:YAG laser trabeculoplasty (selective laser trabeculoplasty): a multicenter, pilot, clinical study. Ophthalmology 105: 2082-2090. [Crossref]

9. Latina MA, Tumbocon JA (2002) Selective laser trabeculoplasty: a new treatmen option for open angle glaucoma. Curr Opin Ophthalmol 13: 94-96. [Crossref]

10. Bovell AM, Damji KF, Hodge WG, Rock WJ, Buhrmann RR, et al. (2011) Long term effects on the lowering of intraocular pressure: selective laser or argon laser trabeculoplasty? Can J Ophthalmol 46: 408-413. [Crossref]

11. Kramer TR, Noecker RJ (2001) Comparison of the morphologic changes after selective laser trabeculoplasty and argon laser trabeculoplasty in human eye bank eyes. Ophthalmology 108: 773-779. [Crossref]

12. Latina MA, Park C (1995) Selective targeting of trabecular meshwork cells: in vitro studies of pulsed and CW laser interactions. Exp Eye Res 60: 359-371. [Crossref]

13. Melamed S, Ben Simon GJ, Levkovitch-Verbin H (2003) Selective laser trabeculoplasty as primary treatment for open-angle glaucoma: a prospective, nonrandomized pilot study. Arch Ophthalmol 121: 957-960. [Crossref]

14. Wong MO, Lee JW, Choy BN, Chan JC, Lai JS (2015) Systematic review and metaanalysis on the efficacy of selective laser trabeculoplasty in open-angle glaucoma. Surv Ophthalmol 60: 36-50. [Crossref]

15. Frezzotti P, Motolese I, Peruzzi S, et al. Selective Laser Trabeculoplasty: Hypotensive Efficacy, Anterior Chamber Inflammation and Postopera 7 tive Pain. Siena, Italy: Department of Surgery, Ophthalmology Unit, University of Siena; 2015.

16. Sayin N, Alkin Z, Ozkaya A, Demir A, Yazici AT, et al. (2013) Efficacy of selective laser trabeculoplasty in medically uncontrolled glaucoma. ISRN Ophthalmol 2013: 975281. [Crossref]

17. Ingvoldstad DD, Krishna R, Willoughby L (2005) Micropulse diode laser trabeculoplasty versus argon laser trabeculoplasty in the treatment of open angle glaucoma. Invest Ophthal Vis Sci 46: 123.

18. Gossage DD. $532 \mathrm{~nm}$ MicroPulse Laser Trabeculoplasty Successfully Lowers IOP as Primary Treatment. Iridex Clinical Case Reports Series.May 7, 2014.

19. Belyea D. Micropulse Laser Trabeculoplasty Versus Selective Laser Trabeculoplasty for Treatment of Open Angle Glaucoma (MLT versus SLT) May 2014.

20. Fea AM, Bosone A, Rolle T, Brogliatti B, Grignolo FM (2008) Micropulse diode laser trabeculoplasty (MDLT): A phase II clinical study with 12 months follow-up. Clin Ophthalmol 2: 247-252. [Crossref]

21. Luttrull JK, Sramek C, Palanker D, Spink CJ, Musch DC (2012) Long-term safety, highresolution imaging, and tissue temperature modeling of subvisible diode micropulse photocoagulation for retinovascular macular edema. Retina 32: 375-386. [Crossref]

22. Lavinsky D, Cardillo JA, Melo LA Jr, Dare A, Farah ME, Belfort R Jr (2011) Randomized clinical trial evaluating mETDRS versus normal or high-density micropulse photocoagulation for diabetic macular edema. Invest Ophthalmol Vis Sci 52: 4314-4323. [Crossref]

23. Koss MJ, Beger I, Koch FH (2012) Subthreshold diode laser micropulse photocoagulation versus intravitreal injections of bevacizumab in the treatment of central serous chorioretinopathy. Eye (Lond) 26: 307-314. [Crossref]

24. Fudemberg, SJ, Myers, JS, Katz, LJ (2008) Trabecular meshwork tissue examination with scanning electron microscopy: a comparison of MicroPulse diode laser (MLT), selective laser (SLT), and argon laser (ALT) trabeculoplasty in human cadaver tissue. Invest Ophthalmol Vis. Sci 49:1236.

25. Ogata N, Tombran-Tink J, Jo N, Mrazek D, Matsumura M (2001) Upregulation of pigment epithelium-derived factor after laser photocoagulation. Am J Ophthalmol 132: 427-429. [Crossref]

26. Detry-Morel M, Muschart F, Pourjavan S (2008) Micropulse diode laser (810 $\mathrm{nm})$ versus argon laser trabeculoplasty in the treatment of open-angle glaucoma: comparative short-term safety and efficacy profile. Bull Soc Belge Ophtalmol (308): 21-28. [Crossref] 
27. Lee JW, Yau GS, Yick DW, Yuen CY (2015) MicroPulse Laser Trabeculoplasty for the Treatment of Open-Angle Glaucoma. Medicine (Baltimore) 94: e2075. [Crossref]

28. Babalola OE (2015) Micropulse diode laser trabeculoplasty in Nigerian patients. Clin Ophthalmol 9: 1347-1351. [Crossref]
29. Hodge WG, Damji KF, Rock W, Buhrmann R, Bovell AM, Pan Y (2005) Baseline IOP predicts selective laser trabeculoplasty success at 1-year post-treatment: results from a randomised clinical trial. Br J Ophthalmol 89: 1157-1160. [Crossref]

30. Ayala M, Chen E (2011) Predictive factors of success in selective laser trabeculoplasty (SLT) treatment. Clin Ophthalmol 5: 573-576. [Crossref]

Copyright: $(02017$ Cornejo DV. This is an open-access article distributed under the terms of the Creative Commons Attribution License, which permits unrestricted use, distribution, and reproduction in any medium, provided the original author and source are credited. 